ISSN: 2162-3104 Print/ ISSN: 2166-3750 Online Volume 6, Issue 4 (2016), pp. 1045-1052 (C) Journal of International Students http://jistudents.org/

\title{
The Plagiarism Polyconundrum
}

\author{
Reine D. Bethany \\ New York Institute of Technology, USA
}

\begin{abstract}
Plagiarism hinders student success because it shortcuts genuine writing practice and incurs penalties when discovered. Although students are aware of its potential consequences, plagiarism continues. This article reflects on the polyconundrum of empathizing with the many hindrances to student writing while deploying strategies to reduce plagiarism and improve academic essay skills.
\end{abstract}

Keywords: documentation, international students' written English, plagiarism, research writing, student success

For international students in particular, solid English writing skills matter. Mastering spoken and written English increases global employability and earning power (Pandey \& Pandey, 2014; Rawlings \& Sue, 2013, p. 31). Learning to write in a second language is hard, and plagiarizing only delays the learning. Yet plagiarism is as common among international students as domestic (Duff, Rogers, \& Harris, 2006). I believe its prevalence is due in significant part to problems that nonnative English speakers encounter when they seek a degree at a native-English-speaking university. In this article, I present several problems that I myself did not predict when I first started teaching international students. I also present my solutions.

\section{REFLECTION ON THE ROOTS OF STUDENT PLAGIARISM}

Over the years, I have learned that plagiarism has many roots: cultural confusion (Duff, Rogers, \& Harris, 2006; Evans \& Youman, 2000; Hu \& Lei, 2015; Mundara \& Chaudhuri, 2007), second-language frustration (Baty \& Caulcutt, 2005), limited resources for help (Hennebry, Lo, \& Macaro, 2012, pp. 225-226), the growing culture of Internet copying-andpasting ("Web Plagiarism Keeps Rising,” 2003; Kim, Hwang, Lee, \& Shim, 
2016), the ineffectiveness of plagiarism penalties as a deterrent (SutherlandSmith, 2010), perceived lack of plagiarism policy enforcement (Austin, Collins, Remillard, Kelcher, \& Chuia, 2006, p. 5), and an attitude of acceptance toward plagiarizing among students (Austin et al., 2006).

My discovery of these roots has helped me devise strategies to address plagiarism to a much greater degree than in the past. For example, in addition to use of electronic detection devices, I describe plagiarism in my syllabus and incorporate reminders during the preparation period for each writing project. Our university librarians pinpoint plagiarism in their research training sessions. When I catch plagiarism, I apply penalties and remediation on a case-by-case basis. To assess student views of plagiarism, I have students write short in-class essays about what plagiarism is and whether they think it should be punished. (They do, though their ideas of fair punishment differ.) Undoubtedly, my students understand all about plagiarism, yet it still occurs.

I have passed through sundry reactions toward plagiarism: shock in the face of deception, embarrassment at my insensitivity to cultural differences, compassion for students' life struggles, disgust at having to play detective, discouragement when plagiarism recurs, and ultimately, a pragmatic peace because I finally realized what plagiarism really is.

Plagiarism is a broad-spectrum solution to a host of problems. Since problems are inevitable, the temptation to plagiarize is here to stay. Having accepted that reality, my discouragement in the face of plagiarism has evaporated because I am no longer striving toward an unreachable outcome. My effort now is to keep updating my awareness of the problems so I can keep refining my antiplagiarism efforts.

\section{IDENTIFYING ISSUES \& SOLUTIONS}

For second-language learners, some issues are predictable. Grammar and vocabulary are the most obvious; students may study for a decade or more to master those elements (Min, 2013; Park, 2009). Other problems are not predictable, such as the occurrence of phrases like "men are a sorry lot," which appears in a translation of Niccoló Machiavelli's "The Qualities of the Prince," but not in second-language manuals or online translation tools - along with countless other idioms and cultural references that are bothersome for domestic students but a stumbling block for internationals. In the list below, I detail several unexpected issues and my solutions.

Issue 1: Concepts of how to express one's original ideas in writing are not universal. Although international students might memorize the basic steps of U.S.-style or British-style expository writing from a textbook or website, this knowledge only partly prepares them for a larger reality: that U.S. or 
British academic essay structure (thesis, supporting points stated directly and succinctly without digression from the thesis, summative conclusion and final point) may differ drastically from customary essay structure in other languages and cultures (Hu, 2014; Kaplan, 2001). Second-language students may memorize their culture's traditional texts to a degree that would astound American students ( $\mathrm{Hu}, 2014)$, or they may have translated countless unrelated sentences into English exercise books during their language studies, yet have had little practice producing complete American or British-style academic essays (Fedderholdt, 2001; Reid, 1997).

Academic essay structure is hard enough for domestic students. It requires that the writer accrue information on a specific topic, decide exactly which main point to make, and then select only the relevant elements of the acquired evidence to support that main point. For nonnative English speakers, the reading task alone can be intimidating. The subsequent decision-making process that leads to a thesis can seem confounding. Only with sustained practice can anyone know for certain if one has produced a workable thesis, a relevant piece of evidence, and a valid concluding idea. The longer and more complex the paper, the more challenging this whole scenario and the easier it is to choose plagiarism when an actual paper comes due.

Solution to Issue 1: Frequent review of the structure and goals of an academic essay throughout a semester develops student familiarity with the academic writing format, boosting students' confidence that they can write acceptably.

Issue 2: Imperfect grammar should not invalidate a well-structured essay. I once thought I should call every grammar problem to a student's attention. Gradually I realized that if my feedback focuses too heavily on students' grammar and mechanics without crediting their ideas, my students feel demeaned (Séror, 2011, p. 126). Negative feeling reduces students' motivation to push themselves to produce original work. Furthermore, if I act as though perfect English grammar is the priority in writing, I put students in an impossible position, because they cannot possibly achieve that perfection.

Solution to Issue 2: One of the most important steps I have taken in teaching international students is identifying what Reid (1997, p. 23) calls "error gravity" - that is, I work hardest on elements of writing that are most likely to impede sense, such as word choice, verb tense, and word order. Mastering these along with academic essay format enables students to assemble an effective paper. In later professional life, when they want to present original research in English, they will have the skills to wrestle their 
evidence and documentation into order, and work with colleagues and editors to address grammar and mechanics.

Issue 3: Writing depends on long-established habits of word use. Creating one's own texts requires, not just a good bilingual dictionary, but intricate knowledge of how words interact in various contexts (see Min, 2013). For example, if exercise means practicing specific skills, as in a grammar exercise, what does a student do with the phrase exercise moderation? Creating texts also requires an inward bank of customary word use; no one in the United States ever says "grass-cutting machine" instead of "lawnmower," or "general people” instead of "general population," yet to a second-language student trying to express a simple, daily concept, these phrases might seem reasonably equivalent. Deployed in an essay, students' creative phrasing causes reader confusion.

Both single words and common phrases may thus present important barriers to second-language writers. For students who learned English from nonnative speakers, or who started learning English in their late teens, there are few word habits to draw upon (Min, 2013). During in-class assignments, I see my students pondering dictionaries and translation tools, trying to pin down idioms or discern between adverbs like much and very while struggling with article and preposition usage ("In one hand, it is much difficult to buy a land in New York. In other hand, a property is big value in future”). The extra time these students invest in a 500-word essay may be hard for domestic professors to imagine.

Solution to Issue 3: During in-class composition, I encourage questions about word usage. Also, I identify potentially confusing words and phrases when I assign texts. During lecture, I spotlight those words and phrases and ask, "Is this usage familiar to you?" Getting students comfortable enough to admit they don't understand is a journey in itself; I tell them that my best friend is the student willing to say, "I don't get it," because if one student voices it, a dozen others are thinking it. Gradually, students themselves identify points of confusion, which we resolve together. Students are more likely to write original work when they are confident that they understand what they have read, and can use new vocabulary in a paper.

Issue 4: Which types of copying constitute plagiarism? For international students, one phrase swimming in an ocean of print looks a lot like another. For example, copying the phrase "burn the midnight oil" would not be plagiarism because that phrase functions as a single word. But if an international student writes, "Activists burned the midnight oil in fight for civil right, because injustice anywhere is a threat to justice everywhere," how does the student know that the last (commonly quoted) eight words are 
from Martin Luther King, Jr.'s, “Letter from a Birmingham Jail” and must be credited?

In fact, isn't there an accepted societal usage of powerful word groups that would not be branded plagiarism? In everyday conversation and writing, do we credit the U.S. Declaration of Independence for the words "all men are created equal"? Rarely. Why? Because we all know the source; we mentally credit it, and don't feel the need to keep recruiting it (though I coach my students to do so when they write). Isn't that the same as using conventional cultural wisdom in one's written work, as is customary in many nations (Duff et al., 2006, p. 675)? How are international students supposed to discern between accepted wise words and plagiarism?

Solution to Issue 4: I give my international students the information to correct such problems as they arise.

Issue 5: Multiple mundane barriers to writing exist. Typing is an example of a mundane yet troublesome barrier. Students accustomed to a nonEnglish keyboard may find English-language typing dauntingly laborious. Forced by time constraints to choose between assignments in their majors and producing original writing, chancing a copy-and-paste may seem a sensible strategy.

Then there is transportation. Students often live in clusters far from campus. During long rides in carpools or on public transport, little homework can be accomplished, making the time-consuming process of good writing even less surmountable.

Also, family expectations intrude. Family may arrive from several thousand miles away and expect a tour of the city on the day my class meets. International students must scout for housing, negotiate car rentals, handle student visa bureaucracy, and maintain GPAs. Combine these difficulties with arduous family communication across up to 12 time zones, and making sure all work is original may seem overwhelming.

Solution to Issue 5: I listen intently when students describe problems, but remind them that I cannot grade them on what they would have done if these problems did not exist. I then ask for a reasonable plan to revise or complete plagiarized or missing classwork, which usually results in honest papers.

Issue 6: Academic documentation. In my experience, many international students struggle with documentation. They can figure out how to put American-style quotation marks around copied material, but knowing when to cite sources in the text can be confounding. Some students think only direct quotes require in-text citation; when they don't cite paraphrased sentences or data, professors may believe the students have plagiarized. In 
reality, the students have picked up on some aspects of the citing picture and missed others.

Further hassles: (a) Discerning which documentation elements belong in an in-text citation and which in the reference list only comes with supported practice. (b) Author names are tricky: Systems of surname and given name vary confusingly among cultures. Even the (supposedly trustworthy!) online reference formatting tools have trouble with names; for example, the site from which I obtained the article by Kim, Hwang, Lee, and Shim (2016) had formatted the reference list entry as Kyong-Jee, K., Jee Young, H., Dong-Wok, L., and Min-Sung, S.--even though their names were listed Western-style as Kyong-Jee Kim, Jee Young Hwang, Dong-Wok Lee, and Min-Sung Shim at the end of the "Letter to the Editor" that they wrote for the English-language journal Medical Education Online. (c) Conventions of capitalization and punctuation vary between British and American English. Many nonnative speakers have learned British English, and students from non-English-speaking European nations have their own norms of capitalization, confounding standards of correctness. It Doesn't Help That Electronic Reference Formatting Tools Apparently Use The "Capitalize Each Word” Toggle That Is A Feature Of Microsoft Word In Their Treatment Of Titles; or that the formatting programs occasionally list unsigned articles as (for example) "New York Times, The."

Solution to Issue 6: As university librarians know, documentation is a comprehensive scenario that requires ongoing professor support, not one or two brush-up sessions. Scheduling ongoing segments of class time for documentation practice helps avert plagiarism by making documentation feel possible (Gourlay \& Deane, 2012, pp. 24-26).

\section{DISCUSSION AND CONCLUSIONS}

One unvarying tactic with which I address the issues I have named is to designate several lecture hours per writing project as writing laboratory time. Second-language students often feel uncertain whether they are using English effectively, and the assurance of immediate feedback from me as they gather evidence and develop a thesis affords them much-deserved support (see San Miguel, Townsend, \& Waters, 2013, pp. 24-25; also Séror, 2011).

Though these strategies help, I am ever watchful. Students' in-class work, recorded in Blackboard, affords me samples of each one's writing that I compare to out-of-class assignments. Sharp contrast in grammar competency between out-of-class and in-class work puts me on alert. If I cannot find electronic evidence of plagiarism, I interview the student. Sometimes a writing coach wrote the paper, making it original and not 
susceptible to electronic detection. "All the ideas are mine," the students say. I then point out that learning to present ideas in written form is the purpose of the class, and it is not my job to grade their writing coach (or their big sister, etc.). Other times, the student had taken the paper to a writing center or to a competent friend, who helped edit too much. (Defining "too much help" is a topic deserving further research.)

If students truly commit what Owens and White (2013) term dishonest plagiarism, I enact our university's plagiarism reporting procedure. This protocol does not normally result in immediate failure, but does establish a record against which future plagiarism attempts may be measured and penalized.

Addressing plagiarism is vital. Demanding that students write their own texts not only makes them into trustworthy researchers. It also trains them to truly assess what they know and don't know, and to embrace the reflective, recursive process required to ensure that their writing meets professional standards. Keeping student writing honest presents a challenge, but to whatever level we professors achieve that goal, we have accomplished a vital service.

\section{REFERENCES}

Austin, Z., Collins, D., Remillard, A., Kelcher, S., \& Chuia, S. (2006). Influence of attitudes toward curriculum on dishonest academic behavior. American Journal of Pharmaceutical Education, 70(3), 1-9.

Baty, P., \& Caulcutt, C. (2005). Poor English skills force foreign students to use translators. Times Higher Education Supplement, 1685, 8.

Duff, A. H., Rogers, D. P., \& Harris, M. B. (2006). International engineering students-avoiding plagiarism through understanding the Western academic context of scholarship. European Journal of Engineering Education, 31(6), 673-681. doi:10.1080/03043790600911753

Evans, F. B., \& Youmans, M. (2000). ESL writers discuss plagiarism: The social construction of ideologies. Journal of Education, 182(3), 49.

Fedderholdt, K. 2001. An email exchange project between non-native speakers of English. English Language Teachers Journal, 55(3), 273.

Gourlay, L., \& Deane, J. (2012). Loss, responsibility, blame? Staff discourses of student plagiarism. Innovations in Education \& Teaching International, 49(1), 19-29. doi:10.1080/14703297.2012.647780

Hennebry, M., Lo, Y. Y., \& Macaro, E. (2012). Differing perspectives of non-native speaker students' linguistic experiences on higher degree courses. Oxford Review of Education, 38(2), 209-230. doi:10.1080/03054985.2011.651312

Hu, M. 2014. Toward the understanding of Chinese ESL writing. English Today, 30(1), 55-59. doi:10.1017/S0266078413000576.

Hu, G., \& Lei, J. (2015). Chinese university students’ perceptions of plagiarism. Ethics \& Behavior, 25(3), 233-255. doi:10.1080/10508422.2014.923313

Kim, K-J., Hwang, J. Y., Lee, D.-W., \& Shim, M.-S. (2016). Medical student 
plagiarism in problem-based learning courses. Medical Education Online, 21, 1. doi:10.3402/meo.v21.30537

Min, Y.-K. (2013). Vocabulary acquisition: Practical strategies for ESL students. Journal of International Students, 3(1), 64-69.

Owens, C., \& White, F. A. (2013). A five-year systematic strategy to reduce plagiarism among first-year psychology university students. Australian Journal of Psychology, 65, 14-21.

Park, J.-K. (2009). English fever in South Korea: Its history and symptoms. English Today, 25(1), 50-57. doi:10.1017/S026607840900008X

Pandey, M., \& Pandey, P. (2014). Better English for better employment opportunities. International Journal of Multidisciplinary Approach and Studies, 1(4), 93-100.

Rawlings, M., \& Sue, E. (2013). Preparedness of Chinese students for American culture and communicating in English. Journal of International Students, 3(1), 29-40.

Reid, J. M. (1997). Which non-native speaker? Differences between international students and U.S. resident (language minority) students. New Directions for Teaching and Learning, 70, 17.

San Miguel, C., Townsend, L., \& Waters, C. (2013). Redesigning nursing tutorials for ESL students: A pilot study. Contemporary Nurse, 44(1), 21-31.

Séror, J. (2011). Alternative sources of feedback and second language writing development in university content courses. Canadian Journal of Applied Linguistics, 14(1), 118-143.

Sutherland-Smith, W. (2010). Retribution, deterrence and reform: The dilemmas of plagiarism management in universities. Journal of Higher Education Policy \& Management, 32(1), 5-16. doi:10.1080/13600800903440519

REINE BETHANY, MA, is an adjunct English professor at the New York Institute of Technology, Old Westbury, New York, and at Nassau Community College in Garden City, New York. An author and local historian, her academic research focuses on impediments to academic writing in both domestic and international students. Email: rbethany@nyit.edu 